\title{
Design and performance evaluation of Fractional ORDER controller for Brushless DC Motor
}

\author{
R. Narmada and M. Arounassalame
}
Department of Electrical and Electronics Engineering, Pondicherry Engineering College, Puducherry, India.
narmadathevi17@gmail.com, arounm@gmail.com

\begin{abstract}
Recent developments and advancements in the areas of permanent magnets, power electronics and modern control technologies have significantly influenced the wide-spread use of Brushless DC (BLDC) motor drives. BLDC motors are now, widely used in many applications such as servo drives, computer peripheral equipments and electric vehicles due to their high power density, high efficiency, compact size and easier control. In this paper a control scheme is presented which uses the traditional PID controller for the speed control of BLDC motor. PID controller is designed both by Zeigler-Nichols tuning method and Genetic Algorithm. A controller based on fractional order PID is also designed using Genetic algorithm and the performances of fractional PID controller are compared with the performance of PID controller. MATLAB/SIMULINK software is used to simulate and test the performances of the designed controllers.
\end{abstract}

Keywords: BLDC motor, PID controller, fractional order PID controller, genetic algorithm

\section{Introduction}

Conventional DC motors are highly efficient and their characteristics make them suitable for use as servomotors. However their only drawback is that they need a commutator and brushes which are subject to wear and require maintenance. When the functions of commutator and brushes were implemented by solid state switches, maintenance free motors were realized. These motors are known as brushless DC motors. The function of magnet is the same in both brushless DC motor and the DC commutator motor. The most obvious advantage of brushless configuration is the removal of brushes. Brush maintenance is no longer required, and many problems associated with brushes are removed [1].

A Brushless Direct Current (BLDC) Motor has a rotor with permanent magnets and has no mechanical commutator which leads to many advantages over brushed DC motors and induction motors. An advantage of the brushless configuration in which the rotor inside the stator is that more cross sectional area is available for the power or armature winding. At the same time conduction of heat through the frame is improved, generally an increase in the electrical loading is possible, providing greater specific torque. The efficiency is likely to be higher that of a commutator motor of equal size and the absence of brush friction help further in this regard. A few of these are: better speed versus torque characteristics, high dynamic response, high efficiency, long operating life, noiseless operation, compact size, cost efficiency, higher speed ranges. BLDC motors are used in high performance industries such as appliances, automotive, aerospace, conveyors, medical electrical bed, rolling transmission equipment, packing machine, pressure pump equipment, cutting machine, labeling print machine, servo drives, computer peripheral equipments, industrial automation equipment and instrumentation[1].

The rest of the paper is organized as follows: In section 2 the modeling of BLDC motor was discussed. In section 3, PID controllers and its tuning methods were given. In section 4, the Fractional PID controllers were discussed. In section 5, the simulations results were discussed in detail and finally conclusions were made in section 6.

Received: August $11^{\text {st }}, 2013$. Accepted: September $13^{\text {rd }}, 2014$ 


\section{Modeling of BLDC}

The star connected, three phase motor with 8 pole permanent magnetic rotor is driven by standard three phase inverter [2]. Figure 1 shows the basic block diagram of Brushless DC motor. The circuit consists of DC supply, three phase inverter and logic circuit. BLDC Motors are driven by DC voltage. BLDC motor is the combination of a permanent magnet synchronous motor and a frequency inverter. Stator is a classic three phase stator like that of an induction motor and rotor has surface mounted permanent magnets. The inverter plays the role of commutator of a conventional DC motor. Hence the combination of permanent magnet ac motor and electronic commutator is said to be Brushless DC motor.

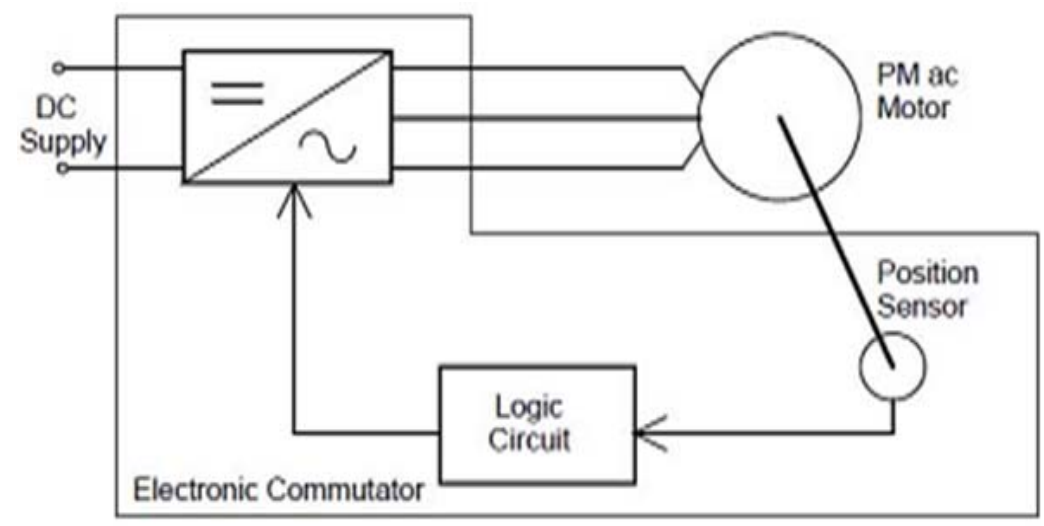

Figure 1. Block diagram of Brushless DC Motor

\section{A. Electrical subsystem}

The electrical part of DC Brushless motor and relationship between current, voltage, and back electromotive force and rotor velocity is derived using Kirchhoff's voltage law [2]:

$$
\begin{aligned}
& \mathrm{v}_{\mathrm{a}}=\mathrm{R}_{\mathrm{a}} \mathrm{i}_{\mathrm{a}}+\mathrm{L}_{\mathrm{a}} \frac{\mathrm{di_{a }}}{\mathrm{dt}}+\mathrm{M}_{\mathrm{ab}} \frac{\mathrm{di} \mathrm{i}_{\mathrm{b}}}{\mathrm{dt}}+\mathrm{M}_{\mathrm{ac}} \frac{\mathrm{di}_{\mathrm{c}}}{\mathrm{dt}}+\mathrm{e}_{\mathrm{a}} \\
& \mathrm{v}_{\mathrm{b}}=\mathrm{R}_{\mathrm{b}} \mathrm{i}_{\mathrm{b}}+\mathrm{L}_{\mathrm{b}} \frac{\mathrm{di}_{\mathrm{b}}}{\mathrm{dt}}+\mathrm{M}_{\mathrm{ba}} \frac{\mathrm{di_{a }}}{\mathrm{dt}}+\mathrm{M}_{\mathrm{bc}} \frac{\mathrm{di}_{\mathrm{c}}}{\mathrm{dt}}+\mathrm{e}_{\mathrm{b}} \\
& \mathrm{v}_{\mathrm{c}}=\mathrm{R}_{\mathrm{c}} \mathrm{i}_{\mathrm{c}}+\mathrm{L}_{\mathrm{c}} \frac{\mathrm{di} \mathrm{i}_{\mathrm{c}}}{\mathrm{dt}}+\mathrm{M}_{\mathrm{ca}} \frac{\mathrm{di}}{\mathrm{dt}}+\mathrm{M}_{\mathrm{cb}} \frac{\mathrm{di}_{\mathrm{b}}}{\mathrm{dt}}+\mathrm{e}_{\mathrm{c}}
\end{aligned}
$$

where $\mathrm{Ra}, \mathrm{Rb}, \mathrm{Rc}:$ stator resistance per phase $[\Omega]$

La, Lb, Lc : Stator inductance per phase $[\mathrm{H}]$

Mab, Mbc, Mca : Mutual inductance between phases [H]

ia, ib, ic : stator current per phase [A]

$\mathrm{va}, \mathrm{vb}, \mathrm{vc}:$ phase voltage of windings [V]

ea, eb, ec : back emfs [V]

\section{B. Mechanical subsystem}

A Mathematical relationship between the shaft angular velocity and input voltage to the brushless DC motor is derived using Newton's law of motion.

$$
\mathrm{J} \frac{\mathrm{d} \omega_{\mathrm{r}}}{\mathrm{dt}}=\mathrm{T}_{\mathrm{e}}-\mathrm{T}_{\mathrm{m}}-\mathrm{F} \omega_{\mathrm{r}}
$$


where $\mathrm{J}$ : inertia of rotor and coupled $\left[\mathrm{kgm}^{2}\right]$

Te : total torque output $[\mathrm{Nm}]$

$\mathrm{Tm}:$ load torque $[\mathrm{Nm}]$

$\mathrm{F}:$ Friction constant $[\mathrm{Nm} /(\mathrm{rad} / \mathrm{sec})]$

$\omega \mathrm{r}:$ rotor speed $[\mathrm{rad} / \mathrm{sec}]$

The angular position is obtained from the integration of the angular velocity.

$$
\theta_{\mathrm{r}}=\int \omega_{\mathrm{r}} \mathrm{dt}
$$

Generated electromagnetic torque for this 3 phase BLDC motor is dependent on the current, speed and Back EMF waveforms, so the instantaneous electromagnetic torque can be represented as:

$$
\boldsymbol{T e}=\frac{1}{\omega_{r}}\left(e_{a} i_{a}+e_{b} i_{b}+e_{c} i_{c}\right)
$$

C. Transfer function

The transfer function of the BLDC motor is given by $[13,14]$

$$
\frac{\omega}{V}=\frac{K t / J L a}{s^{2}+\frac{J R a+F L a}{J L a} s+\frac{F R a+K t K e}{J L a}}
$$

where $\mathrm{Kt}$ is torque constant

and $\mathrm{Ke}$ is back emf constant

Considering the following assumptions:

1. The friction constant is small, i.e. $\mathrm{F}$ tends to 0 , this implies that

2. JRa $>>$ FLa and

3. $\mathrm{KtKe}>>\mathrm{FRa}$

The transfer function can be written as

$$
\frac{\omega}{V}=\frac{K t}{s^{2} J L a+s J R a+K t K e}
$$

Motor Parameters

Table 1 show the BLDC motor specifications which is used in the present simulation study. The rated power of the motor is $1 \mathrm{~kW}$. $500 \mathrm{~V}$ bus voltage is applied to the system.

Table 1. Parameters and constants of BLDC motor

\begin{tabular}{|l|l|}
\hline Rated Speed & $3000 \mathrm{rpm}$ \\
\hline Supply Voltage (V) & $500 \mathrm{~V}$ \\
\hline Stator Resistance & $2.8750 \mathrm{ohms}$ \\
\hline Stator Inductance & $8.5 \mathrm{mH}$ \\
\hline Moment of Inertia & $0.8 \mathrm{e}-3 \mathrm{Kg}-\mathrm{m}^{2}$ \\
\hline Friction Co-efficient & $1 \mathrm{e}-3 \mathrm{Nm} / \mathrm{rad} / \mathrm{sec})$ \\
\hline Back emf constant & $84.64 \mathrm{~V} / \mathrm{krpm}$ \\
\hline Torque constant & $1.4 \mathrm{~N} \cdot \mathrm{m} / \mathrm{A}$ \\
\hline
\end{tabular}

D. Description of driving circuit

The equivalent circuit of BLDC is given in Figure 2. The circuit consists of three phase power converter which utilizes six power transistors to energize two BLDC motor phases 
concurrently. The rotor which determines the switching sequence of the transistors is detected by means of 3 hall sensors mounted on the stator [15].

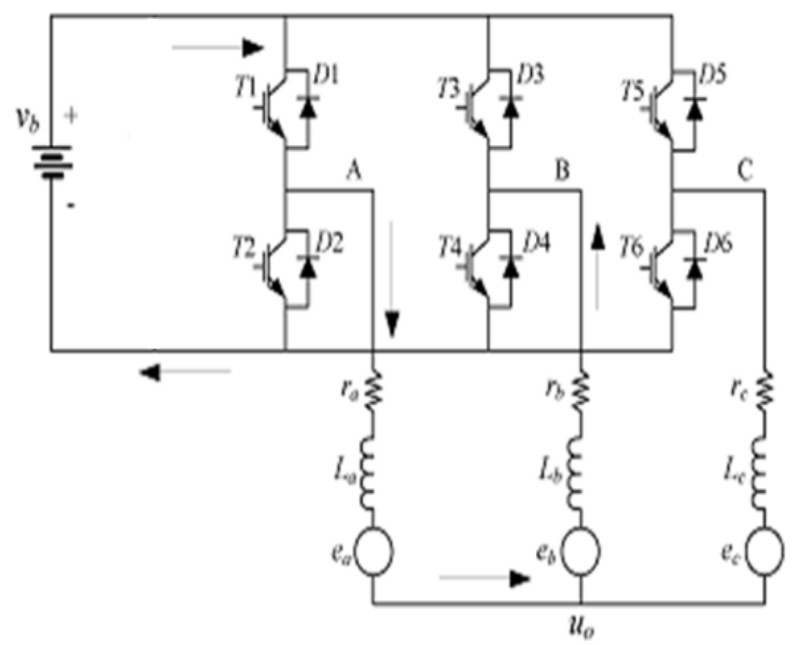

Figure 2. Equivalent circuit of BLDC

By using Hall sensor information, decoder block generates signal vector of back EMF. The basic idea of running the motor in opposite direction is by giving opposite current. Based on that, we have Table 2 and Table 3 for calculating back Emf for clockwise and anticlockwise direction of motion as shown below. The gate logic to transform electromagnetic forces to the 6 signal on the gates is given below in Table 4 [2].

Table 2. Clockwise rotation

\begin{tabular}{|c|c|c|c|c|c|}
\hline Hall sensor A & Hall sensor B & Hall sensor C & EMF A & EMF B & EMF C \\
\hline 0 & 0 & 1 & 0 & -1 & 1 \\
\hline 0 & 1 & 0 & -1 & 1 & 0 \\
\hline 0 & 1 & 1 & -1 & 0 & 1 \\
\hline 1 & 0 & 0 & 1 & 0 & -1 \\
\hline 1 & 0 & 1 & 1 & -1 & 0 \\
\hline 1 & 1 & 0 & 0 & 1 & -1 \\
\hline
\end{tabular}

Table 3. Anticlockwise rotation

\begin{tabular}{|c|c|c|c|c|c|}
\hline Hall sensor A & Hall sensor B & Hall sensor C & EMF A & EMF B & EMF C \\
\hline 0 & 0 & 1 & 0 & 1 & -1 \\
\hline 0 & 1 & 0 & 1 & -1 & 0 \\
\hline 0 & 1 & 1 & 1 & 0 & -1 \\
\hline 1 & 0 & 0 & -1 & 0 & 1 \\
\hline 1 & 0 & 1 & -1 & 1 & 0 \\
\hline 1 & 1 & 0 & 0 & -1 & 1 \\
\hline
\end{tabular}


Table 4. Gate logic

\begin{tabular}{|c|c|c|c|c|c|c|c|c|}
\hline EMF A & EMF B & EMF C & T1 & T2 & T3 & T4 & T5 & T6 \\
\hline 0 & 0 & 0 & 0 & 0 & 0 & 0 & 0 & 0 \\
\hline 0 & -1 & 1 & 0 & 0 & 0 & 1 & 1 & 0 \\
\hline-1 & 1 & 0 & 0 & 1 & 1 & 0 & 0 & 0 \\
\hline-1 & 0 & 1 & 0 & 1 & 0 & 0 & 1 & 0 \\
\hline 1 & 0 & -1 & 1 & 0 & 0 & 0 & 0 & 1 \\
\hline 1 & -1 & 0 & 1 & 0 & 0 & 1 & 0 & 0 \\
\hline
\end{tabular}

\section{PID CONTROLLERS}

The Proportional-Integral-Derivative controller is the most common and useful algorithm in control systems engineering. In most cases, feedback loops are controlled using PID Algorithm. The PID controller is always designed to correct error(s) between measured value(s) and set point values in a system.

\section{A. Designing PID controller using Ziegler Nichols method}

The PID controller design by using Ziegler-Nichols method was done using the open loop transfer function and thereafter obtaining the necessary parameter values needed for the evaluation of the P, PI and PID parameters. This method requires the step response of open loop system [5, 6, 8].The step response of open loop system is characterized by two main parameters, the delay time parameter $(\mathrm{L})$ and time constant $(\mathrm{T})$. These two parameters are computed by drawing tangent to the open loop step response at its inflection point as shown in figure 3 .

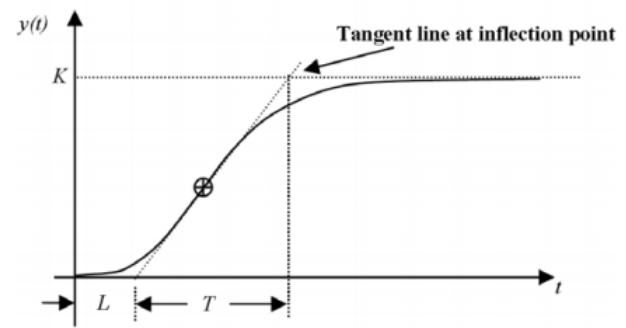

Figure 3. Figure showing the tangent at inflection point

The Ziegler Nichols PID tuning rules from the values of $\mathrm{L}$ and $\mathrm{T}$ are given in Table 5.

Table 5. Zeigler Nichols tuning rule

\begin{tabular}{|l|l|l|l|}
\hline Parameter & Kp & Ti & Td \\
\hline PID Tuning rule & $1.2 \times \frac{\mathrm{T}}{\mathrm{L}}$ & $2 \times \mathrm{L}$ & $0.5 \times \mathrm{L}$ \\
\hline
\end{tabular}

\section{B. Design of PID controller using genetic algorithm}

Genetic Algorithms (GA's) are a stochastic global search method that mimics the process of natural evolution. It is one of the methods used for optimization $[3,4,7]$

\section{Initialization of parameters}

The Genetic Algorithm has to be initialized before the algorithm can proceed. The Initialization of the population size, variable bounds and the evaluation function are required [11]. These are the initial input that is required in order for the Genetic Algorithm process to start. The initial choices for the present case are given in the Table 6 . 
Table 6. Initial choices of GA

\begin{tabular}{|l|l|}
\hline Population size & 100 \\
\hline Bounds & 50 \\
\hline Crossover type & Arithmetic crossover \\
\hline Mutation type & Uniform mutation \\
\hline
\end{tabular}

Objective function for Genetic algorithm

Objective function is required to evaluate the best gain values of PID controller for the system. An objective function could be created to find a PID controller that gives the smallest overshoot, fastest rise time or quickest settling time. The error functions such as Integral of Absolute error (IAE) is used as objective functions in this work. To minimize the error, the fitness function is define as

Fitness function $=\frac{1}{\mathrm{IAE}}$

\section{Fractional PID Controller}

Fractional Calculus:

The concept of fractional order controller describes the controllers which are described by using fractional calculus [12]. Fractional calculus involves a fundamental operator ${ }_{a} D_{t}^{r}$, called fractional operator, where a and $t$ are the limits of the operation [10]. The continuous integrodifferential operator is defined as

$$
{ }_{a} D_{t}^{r}=\left\{\begin{array}{cc}
\frac{d^{r}}{d t^{r}} & \Re(r)>0 \\
1 & \Re(r)=1 \\
\int(d \tau)^{-1} & \Re(r)<0
\end{array}\right.
$$

where $\mathrm{r}$ is the order of the operation. A commonly used definition of the fractional differentiation is the Riemann-Liouville definition which is given in [5].

$$
{ }_{a} D_{t}^{r} f(t)=\frac{1}{\Gamma(n-r)} \frac{d^{n}}{d t^{n}} \int_{a}^{t} \frac{f(\tau)}{(t-\tau)^{(r-n+1)}} d \tau
$$

Another definition for fractional differentiation, is the Grunwald-Letnikov definition and is given by

$$
{ }_{a} D_{t}^{r} f(t)=\lim _{h \rightarrow 0} h^{-r} \sum_{j=0}^{(t-a) / h}(-1)^{j}\left(\begin{array}{l}
r \\
j
\end{array}\right) f(t-j h)
$$

The operator ${ }_{a} D_{t}^{r}$ is the common for fractional derivative and fractional integration. The fractional order differential equation can be written as

$$
\begin{aligned}
& a_{n} D^{\alpha_{n}} y(t)+a_{n-1} D^{\alpha_{n-1}} y(t)+\ldots+a_{0} D^{\alpha_{0}} y(t) \\
& =b_{m} D^{\beta_{m}} u(t)+b_{m-1} D^{\beta_{m-1}} u(t)+\ldots+b_{0} D^{\beta_{0}} u(t)
\end{aligned}
$$

The transfer function of the fractional order system is given by 


$$
\frac{Y(s)}{U(s)}=\frac{b_{m} s^{\beta m}+b_{m-1} s^{\beta m-1}+\ldots b_{0} s^{\beta 0}}{a_{n} s^{\alpha m}+a_{n-1} s^{\alpha m-1}+\ldots a_{0} s^{\alpha 0}}
$$

Fractional order PID controller is denoted as $P I^{\lambda} D^{\mu}$ which involves an integrator of order $\lambda$ and a differentiator of order $\mu$. These orders can be real numbers as against the conventional integers. The transfer function of such a controller can be written as

$$
G_{C}(s)=K_{P}+\frac{K_{I}}{s^{\lambda}}+K_{D} s^{\mu} \text { where } \lambda, \mu>0
$$

The main advantages of the FO controllers are,

(i) To increase the speed of the response, and to decrease the steady state error and relative stability, for proportional action.

(ii) To increase the relative stability and the sensitivity to noise, for derivative action

(iii) To eliminate the steady state error and to decrease the relative stability, for integral action

The control signal $\mathrm{u}(\mathrm{t})$ can be expressed in the time domain as

$$
u(t)=K_{P} e(t)+K_{I} D^{-\lambda} e(t)+K_{D} D^{\mu} e(t)
$$

If $\lambda=1, \mu=1$, the controller is a integer order PID controller. If $\lambda=1, \mu=0$ the controller is a integer order PI controller. If $\lambda>0, \mu=0$, the controller is a fractional order PI controller. The classical integer order PID controllers are special type of fractional order controllers with $\lambda=1, \mu=1$. It is always expected that the fractional PID controller may enhance the system performance and provide better control of dynamic systems.

\section{Design of FOPID controller using genetic algorithm}

'Genetic Algorithms (GA's) can also be used to design the parameters of FOPID controllers similar to that of integer order PID controllers [11]. The additional parameters to be tuned using GA are the order of integrator and the order of differentiator.

\section{Initialization of parameters}

The Genetic Algorithm has to be initialized before the algorithm can proceed. The same initialization parameters used in Table 6 for the population size, variable bounds and the evaluation function are chosen.

Objective function for Genetic algorithm

Objective function is required to evaluate the best gain values of FOPID controller for the system. An objective function could be created to find a FOPID controller that gives the smallest overshoot, fastest rise time or quickest settling time. The error functions such as Integral of Absolute error (IAE) is used as objective functions in this work. To minimize the error, the fitness function is defined as,

Fitness function $=\frac{1}{\mathrm{IAE}}$

\section{Simulation Results}

Response of Closed loop system using PID controller (Ziegler Nichols Method):

Ziegler Nichols method uses open loop response of the system to determine the PID parameters. The open loop speed response for a step change in the input is obtained. By 
drawing tangent at inflection point, delay and constant time parameters are obtained. With these parameters, PID gain values $\left(\mathrm{K}_{\mathrm{P}}, \mathrm{K}_{\mathrm{I}}\right.$, and $\left.\mathrm{K}_{\mathrm{D}}\right)$ are obtained. The values obtained for the chosen BLDC motor are given in Table 7:

Table 7. Controller values using Ziegler-Nichols method

\begin{tabular}{|c|l|}
\hline Parameters & \multicolumn{1}{|c|}{ Values } \\
\hline $\mathbf{K p}$ & 1.182 \\
\hline $\mathbf{K}_{\mathbf{I}}$ & 1744.80 \\
\hline $\mathbf{K}_{\mathbf{D}}$ & 2.002 \\
\hline
\end{tabular}

By using the controller gain values shown in table 7, the closed loop speed response for the BLDC motor is obtained and is shown in figure 4.

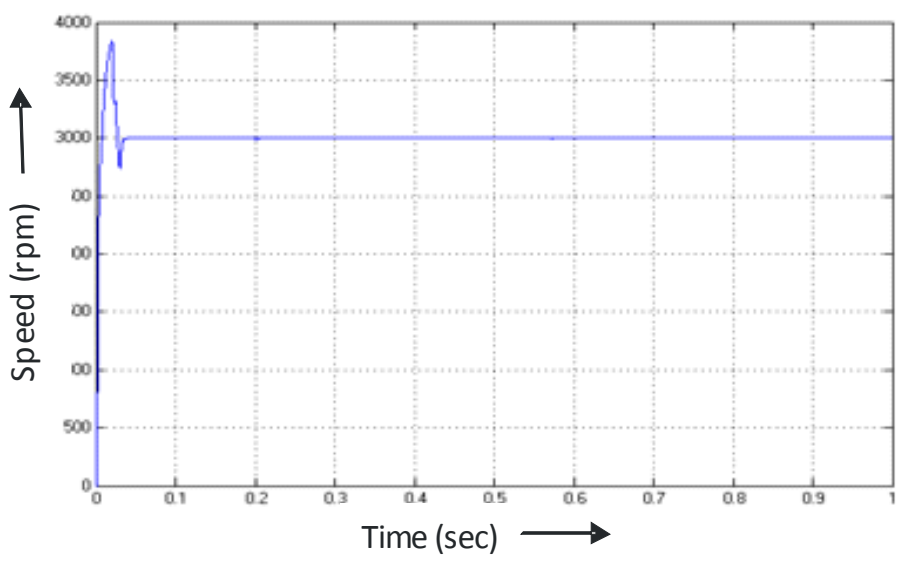

Figure 4. Speed response tuned by Ziegler Nichols

From the figure 4, it is found that the performance of the closed loop system with controller (obtained using Zeigler-Nichols tuning method) has high peak overshoot and more settling time. Transients are very high after applying the load and are shown in figure 5. From figure 5, it is clear that sudden load changes create huge transients in the output response of the closed loop system. The transients die out after long time only.

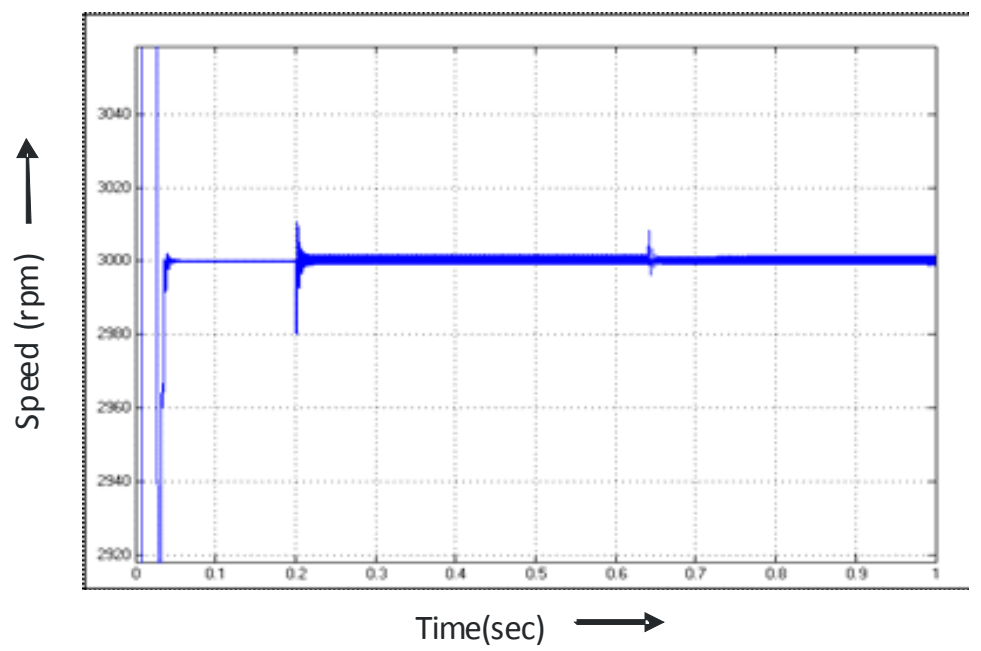

Figure 5. Speed response tuned by Ziegler Nichols 
In order to minimize these transients and reduce the peak overshoot, we design parameters of the PID controller using Genetic Algorithm

Response of Closed loop system using PID controller (GA tuned):

Genetic Algorithm, the global optimization method is used here to tune the PID gain values $\left(\mathrm{K}_{\mathrm{P}}, \mathrm{K}_{\mathrm{I}}, \mathrm{K}_{\mathrm{D}}\right)$.In this method the initial population is chosen as 100 with different variable bounds. PID parameters obtained using GA optimization (IAE minimization) is given in table 8 .

Table 8: Controller values designed using GA

\begin{tabular}{|c|c|c|}
\hline $\mathbf{K}_{\mathbf{P}}$ & $\mathbf{K}_{\mathbf{I}}$ & $\mathbf{K}_{\mathbf{D}}$ \\
\hline 0.0666 & 49.9185 & 0.0076 \\
\hline
\end{tabular}

By using the above gain values in the PID controller, the speed response for the closed loop system is obtained and is shown in figure 6.

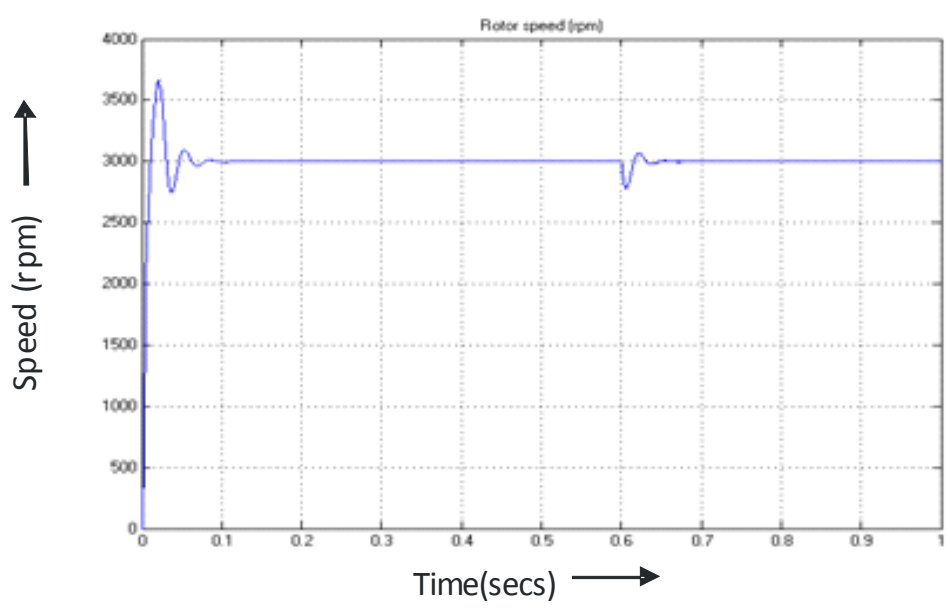

Figure 6. Speed response tuned by GA

From the graph of figure 6 , it is observed that the peak overshoot is reduced considerably as compared to the Zeigler Nichols PID controller. The motor is subjected to different types of loading. Speed of the motor increases or decreases after applying the load, but the response settles faster to the steady state value. It is found that the speed response obtained by using PID controller obtained by minimizing IAE has very less overshoot.

Response of Closed loop system using FOPID controller:

Genetic Algorithm is used here to tune the FOPID gain values $\left(\mathrm{K}_{\mathrm{P}}, \mathrm{K}_{\mathrm{I}}, \mathrm{K}_{\mathrm{D}}, \lambda, \mu\right)$. In this method also the initial population is chosen as 100 with different variable bounds. FOPID parameters obtained using GA optimization (IAE minimization) is given in table 9.

Table 9. FOPID Controller values designed using GA.

\begin{tabular}{|c|c|c|c|c|}
\hline $\mathbf{K}_{\mathbf{P}}$ & $\mathbf{K}_{\mathbf{I}}$ & $\mathbf{K}_{\mathbf{D}}$ & $\boldsymbol{\lambda}$ & $\boldsymbol{\mu}$ \\
\hline 0.044 & 49.73 & 0.153 & 0.97 & 0.39 \\
\hline
\end{tabular}

The speed response of the system with the FOPID controller is shown in figure 7. It is found that the peak overshoot has been reduced drastically and the response settles to the steady state value smoothly. On application of sudden load the closed loop response shows very small deviation and that too settles immediately. 
R. Narmada, et al.

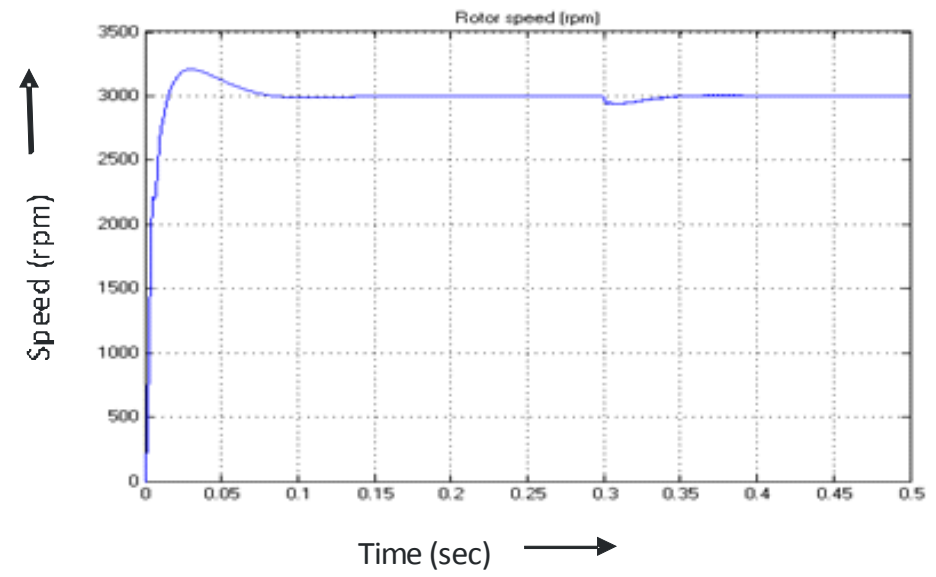

Figure 7. Speed response of FOPID controller

\section{Comparison of Controllers:}

The conventional PID controller and Fractional order PID controller are tuned by Genetic Algorithm and the responses are compared on loading condition and different reference speeds. The Speed response of BLDC with FOPID and PID are shown in figure 8.

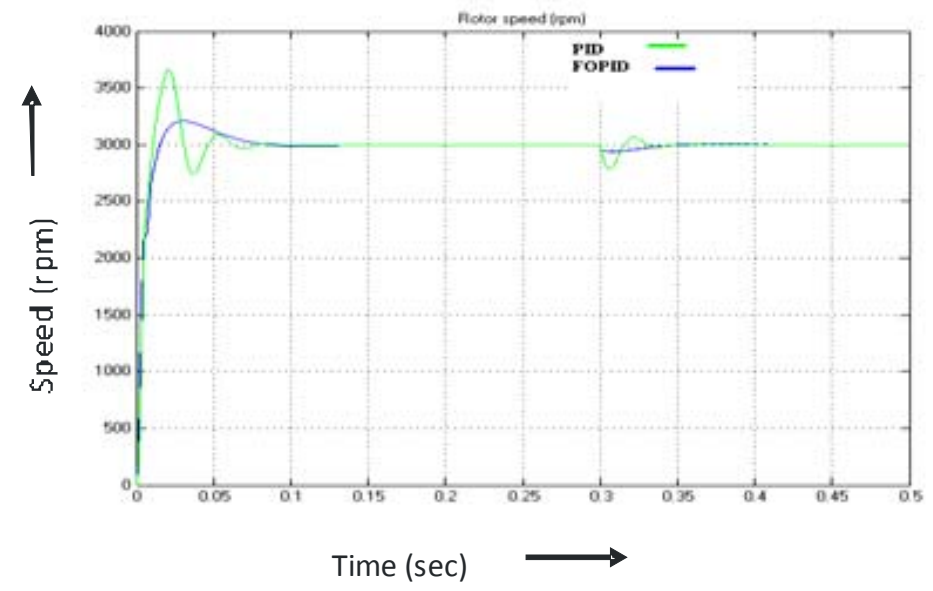

Figure 8. Speed response of BLDC with FOPID and PID

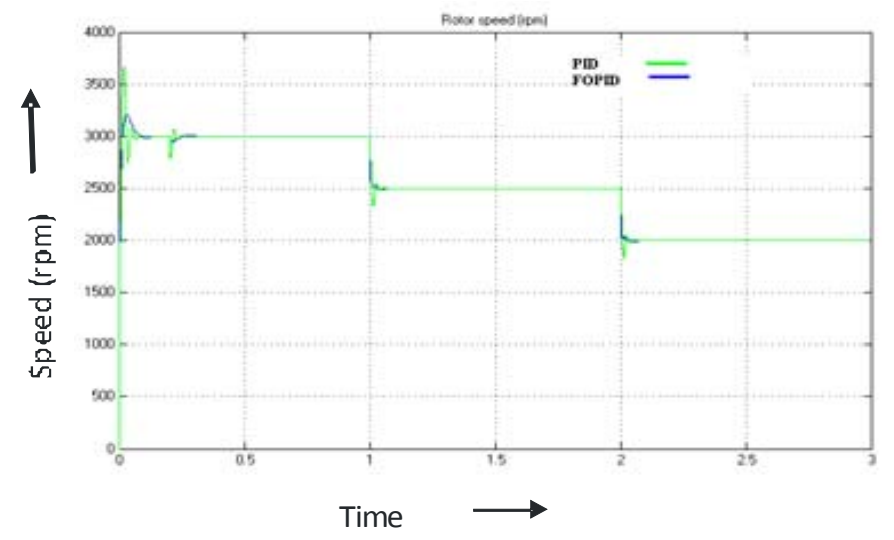

Figure. 9. Speed response of BLDC with FOPID and PID 
From the graph of figure 8, it is clear that the response of the closed loop system with FOPID has less peak overshoot. After applying load, speed decreases slightly and then controlled to the desired speed.

The system is subjected to different speeds at different intervals and the response for system with PID and FOPID are shown in figure 9.

The Reference speed is changed at different time intervals. When the speed is changed, the response of the system shows more overshoot and undershoot in case of PID controller whereas in Fractional order PID controller speed settles smoothly without any remarkable overshoot and undershoot. The various parameters such as peak overshoot, settling time and error are compared for the closed loop system with PID and FOPID controller and are shown in Table 10

Table 10. Comparison of performances of controllers:

\begin{tabular}{|l|l|l|}
\hline \multicolumn{1}{|c|}{ Performance measures } & \multicolumn{1}{c|}{ FOPID } & \multicolumn{1}{c|}{ PID } \\
\hline PEAK OVERSHOOT (\%) & $5.12 \%$ & $22 \%$ \\
\hline SETTLING TIME(sec) & 0.1 & 0.16 \\
\hline IAE & 0.055 & 0.176 \\
\hline
\end{tabular}

\section{Conclusions}

In this work, the control of BLDC using integer order PID and Fractional order PID control algorithms was analyzed. In this work initially the BLDC motor was analyzed with voltage supply of 500 volts. The speed of the BLDC motor in this open loop configuration remains at a constant value. When the load is applied, the response has steady state error. Hence to maintain the speed at rated value even after applying load, controller was used.

For PID controller, the PID gain values were obtained by using Ziegler Nichols method and Genetic Algorithm. For the FOPID controller, the controller parameters are tuned using the Genetic algorithms. The performance of the system with these controllers was analyzed and it is found that the performance of the system with FOPID controller is better in terms of reduction in peak overshoot, good settling time, good tracking of reference speed and maintaining the speed even while applying the torque.

\section{References}

[1] Fernando Rodriguez, Ali Emadi," A Novel Digital control Technique for Brushless DC motor Drives", IEEE Transaction on industrial Electronics Vol.54, No.5, October 2007

[2] Uzair Ansari, Saqib Alam, Syed Minhaj un nabi jafri, "Modeling and control of three phase BLDC motor using PID with Genetic Algorithm", IEEE $13^{\text {th }}$ International conference on modeling and simulation, 2011

[3] K. N Sujatha, K.Vaisakh and G.Anand, "Artificial Intelligence based speed control of brushless DC motor", IEEE power and energy society general meeting, pp. 1-6, July 2010

[4] S.Ravi, P. A. Balakrishnan,"Genetic Algorithm based temperature controller for plastic extrusion system", ICGST_ACSE journal, Volume 11, June 2011

[5] K. Ang, G. Chong,and Y. Li, "PID control system analysis, design, and technology", IEEE trans. control system technology, vol.13, July 2005

[6] Atef Saleh Othman Al-Mashakbeh, "Proportional Integral and Derivative Control of Brushless DC motor", European journal of Scientific Research 26-28, Vol. 35, July 2009.

[7] T. O. Mahony, C. J. Dowing and K. Fatla, "Genetic Algorithm for PID Parameter optimization:Minimizing Error Criteria", Process control and instrumentation 26-28 July 2000, university of Stracthlyde.

[8] Oludayo John Oguntoyinbo, "PID control of Brushless DC motor and robot trajectory planning and Simulation with Matlab/Simulink", Technology and communications, University of applied sciences, 2009. 
[9] F. Rodriguez and A. Emadi, "A Novel Digital Control Technique for Brushless DC Motor Drives: Conduction-Angle Control," IEEE Intern. Elect. Mach. And Drives Conf., pp. 308 -314, May 2005.

[10] Yang Quan Chen, Ivo Petras and Dingyu Xue, "Fractional order control-A Tutorial", American control conference, 2009.

[11] Chunna Zhao, Dingyu Xue and YangQuan Chen," A Fractional Order PID Tuning Algorithm for A Class of Fractional Order Plants" Proceedings of the IEEE International Conference on Mechatronics \& Automation, Niagara Falls, Canada, July 2005

[12] Dingyu Xuet and YangQuan Chen, "A Comparative Introduction of Four Fractional Order Controllers " Proceedings of the 4th World Congress on Intelligent Control and Automation, June 10-14, 2002.

[13] Anand Sathyan, Digital PWM control of Brushless DC(BLDC) motor drives, Ph.D. thesis, Illinois Institute of technology, Chicago, Illinois, 2008.

[14] Alberto A portillo, Michael Frye and Chunjiang Qian, "Particle swarm optimization for PID tuning of a BLDC motor", Proceedings of the IEEE international conference on Systems, Man and Cybernetics, San Antonio, TX, USA, 2009.

[15] Tae-Sung Kim, Byoung-Gun Park, Dong-Myung Lee, Ji-Su Ryu, and Dong-Seok Hyun, "A new approach to sensorless control method for Brushless DC Motors", International journal of control, automation and systems, vol. 6, no. 4, pp. 477-487, 2008.

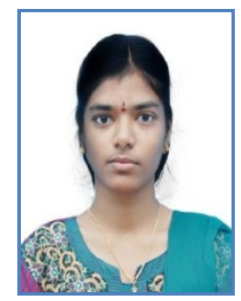

R. Narmada received the B. Tech. degree from Pondicherry University, Pondicherry, India in 2010 and M. Tech. degree from Pondicherry University, Pondicherry, India in 2012. Presently she is working as Assistant professor in Sri Manakula Vinayagar Engineering College, Puducherry, India. Her research interests include special machines, controller design and analysis for electrical systems, and power converters.

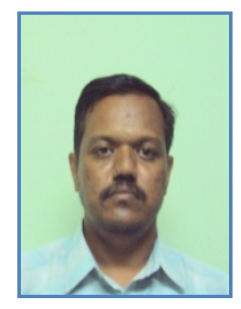

M. Arounassalame received the B.Tech. degree from Pondicherry University, India in 1993 and M.Tech. degree from University of Calicut, India in 1998. He received the $\mathrm{Ph}$. D. degree in systems and control engineering from IIT Bombay, India in 2009. Presently, he is working as an Associate professor in the Department of Electrical and Electronics Engineering, Pondicherry Engineering College, India. His research interests include fractional order control, applications of global optimization algorithms to robust stability analysis and control, and nonlinear circuit analysis. 